\title{
Hepatoprotective and antioxidant activity of Ipomoea staphylina Linn
}

\author{
Ramachandran Jeyadevi ${ }^{1}$, Devanesan Arul Ananth ${ }^{2}$ and Thilagar Sivasudha ${ }^{1 *}$
}

\begin{abstract}
Background: Medicinal and aromatic plants have the potential to treat various disorders both human and animals. This present work investigated the hepatoprotective and antioxidant potential of aqueous extract of Ipomoea staphylina leaves on Wistar rats against $\mathrm{CCl}_{4}$-induced liver injury.

Methods: In vitro free radical scavenging activity of aqueous extract of Ipomoea staphylina (AIS) was estimated using ABTS [2, 2-azino-bis (3-ethylbenzthiazoline-6-sulphonic acid)\} and DPPH (2, 2-diphenyl-1-picrylhydrazyl) free radicals. Pharmacologically important phytochemicals such as phenolic compounds and flavonoids were analyzed using HPLC technique. Hepatotoxicity was induced by oral administration of $\mathrm{CCl}_{4}$ at $1 \mathrm{~mL} / \mathrm{kg}$ body weight of Wistar rats twice a week for 8 weeks. Experimental rats received AlS orally at the doses of 250 and $500 \mathrm{mg} / \mathrm{kg}$ daily for 8 weeks. Silymarin, a routine hepatoprotective drug, was used as a reference drug.

Results: Total phenolics and flavonoid content of AIS are $20.78 \pm 0.86 \mathrm{mg}$ of GAE/g and $17.78 \pm 0.45 \mathrm{mg}$ of RE/g of extract respectively. ABTS and DPPH free radical scavenging activity of AIS exhibits the $I_{50}$ value of $32.08 \pm 0.12$ and $45.24 \pm 0.65 \mu \mathrm{g} / \mathrm{mL}$ respectively. HPLC analysis of AIS showed the presence of polyphenolic compounds such as protocatechuic acid, chlorogenic acid, caffeic acid, vanillin, p-coumaric acid, naringinin, qurecetin, rutin and flavon. Treatment with AIS restored the biochemical parameters towards normal level, prevented the occurrence of LPO and significantly $(P \leq 0.05)$ increased the levels of enzymatic (SOD and catalase) and non-enzymatic (reduced glutathione) antioxidants in $\mathrm{CCl}_{4}$ administered Wistar rats. Histopathology results confirmed the hepatoprotective effect of AIS.
\end{abstract}

Conclusion: Based on the results obtained, we suggest that the I. staphylina leaves extract have potent antioxidant and hepatoprotective activity.

Keywords: Antioxidant, Hepatoprotective, Liver diseases, Medicinal plants

\section{Introduction}

Liver provides protection to an organism against foreign particles by eliminating them, through the process of excretion [1]. Liver damage caused by various hazardous chemicals such as carbon tetrachloride $\left(\mathrm{CCl}_{4}\right)$, thioacetamide, chronic alcohol consumption, and even some drugs used to treat various diseases, may accumulate in the liver tissue and cause alteration in the normal physiological function of the liver by generating free radicals, which is the major reason for the cause of heart related problems like stroke, autoimmune diseases like rheumatoid arthritis, diabetes, and cancer [2]. Patients with liver injury reported to have oxidative stress. The

\footnotetext{
* Correspondence: sudacoli@yahoo.com; sudha@bdu.ac.in

${ }^{1}$ Department of Environmental Biotechnology, Bharathidasan University,

Tiruchirappalli, Tamil Nadu 620024, India

Full list of author information is available at the end of the article
}

imbalance in the level of pro-oxidants and antioxidants leads to oxidative stress leads to potential damage for the organism [3]. Currently available synthetic drugs used for the treatment of liver diseases are inadequate and known for various side effects. Earlier scientific studies reported that, the use of plant phenolics, reduces the risk of liver diseases by acting as antioxidants [4]. Recently, interests in consuming edible plants that are rich in antioxidants and health-promoting phytochemicals have been increased worldwide. $\mathrm{CCl}_{4}$ is frequently used chemical for inducing liver damage in experimental animals $[5,6] . \mathrm{CCl}_{4}$ is a potent hepatotoxin, when administrated leads to necrosis in liver tissue, ultimately leads to liver injury. $\mathrm{CCl}_{4}$ induced liver injury depends on metabolism of toxic substance by the liver NAPDH-cytochrome system results in the formation of 
highly reactive intermediate trichloromethyl free radicals, which binds to cell protein covalently which leads to membrane lipid peroxidation and finally cell necrosis.

India is the land of medicinal plants and it is important to register the data by scientific researches on such plants could be of clinical importance. Treating various health issues like cancer, arthritis, diabetes has been documented in Ayurvedic medical system practiced mainly in the Asian continents for more than 5000 years [7]. Ipomoea staphylina Linn. (Convolvulaceae) is widely found in Asian countries including Sri Lanka, India, and China. In Asian traditional medicine system, I. staphylina is an extensive climber, commonly used for the treatment of liver diseases, purgation, stomach disorders, pain, inflammation, and in rheumatism [8]. Plants of the same genus such as Ipomoea hederacea [9] and Ipomoea obscura [10] have been reported for their hepatoprotective activity. Recently, antimicrobial activity of aqueous extract of Ipomoea reniformis has been reported [11]. The antioxidant and hepatoprotective activity of of $I$. staphylina has not been evaluated scientifically till now. Therefore, identification of phytocompounds from I. staphylina aquous leaves extract (AIS) and evaluate its antioxidant and hepatoprotective activity against $\mathrm{CCl}_{4}$ induced oxidative damage in Wistar rats was the main aim of this research.

\section{Methodology}

\section{Chemicals}

All the chemicals used were of great purity and sensible grade. High quality chemicals used in the research were bought from Sigma Chemicals Co. (St. Louis, MO, USA) like $\mathrm{CCl}_{4}$, Folin's reagent, $\mathrm{Na}_{2} \mathrm{CO}_{3}, \mathrm{AlCl}_{3}, \mathrm{NaCl}, \mathrm{KCl}, \mathrm{K}_{2} \mathrm{~S}_{2} \mathrm{O}_{8}$, $\mathrm{Na}_{2} \mathrm{HPO}_{4}, \mathrm{KH}_{2} \mathrm{PO}_{4}, \mathrm{H}_{2} \mathrm{O}_{2}$,gallic acid, sodium nitrite, rutin, $\mathrm{C}_{2} \mathrm{HCl}_{3} \mathrm{O}_{2}$, DPPH, ABTS, $\mathrm{C}_{6} \mathrm{~N}_{6} \mathrm{FeK}_{3}$, BHT and $\mathrm{FeCl}_{3}$.

\section{Plant collection and extraction}

Plants sample collection and extraction preperations were done by standard protocol followed in Plant metabolite lab, Department of Environmental Biotechnology, Bharathidasan University, Trichirappalli. I. staphylina plants samples were collected from local areas near Bharathidasan University, Tiruchirappalli district, Tamilnadu, India and authenticated in the Department of Plant Science, Bharathidasan University, Tiruchirappalli, Tamil Nadu, India (Collection number 1002, Centre for Research and development of Siddha-Ayurveda Medicines, Bharathidasan University). Leaves were picked, washed, shade dried and ground to powder. Ten grams of the powder was extracted with $250 \mathrm{~mL}$ of distilled water (in the ratio 1:25), by proper shaking for 2 days. Whatmann filter paper No.1 was used to filter the extract and followed by lyophilization using a vacuum freeze dryer (Christ alpha 1-2/LD plus, Osterode am Harz,Germany) to produce a yield of $10 \%$ of dry extract. The dried extract was stored at $-20^{\circ} \mathrm{C}$ in deep freezer for further study. The extract was dissolved in distilled water of known concentrations and used for experimental studies [11].

\section{Determination of total phenolic content}

Total phenolic content was determined by the standardized protocol [12]. To $100 \mu \mathrm{L}$ of the AIS (aquous extract of I. staphylina), $1.5 \mathrm{~mL}$ of distilled water and $300 \mu \mathrm{L}$ of Folin-Ciocalteu reagent was added and incubated for 6 min at room temperature. Then, $300 \mu \mathrm{L}$ of sodium carbonate $(2 \mathrm{~g} / 10 \mathrm{~mL})$ was added and allowed to stand for 30 min at $40^{\circ} \mathrm{C}$ for colour development. Absorbance was read at $765 \mathrm{~nm}$ using the spectrophotometer (Shimadzu UV-1601, Columbia, MD, USA). Commercial gallic acid was used as the standard. Total phenolic content was expressed as mg of GAE/g of extract.

\section{Determination of total flavonoids content}

Total flavonoids content was estimated using the method of Ordon ez et al. [13]. The above mentioned method was standardized in our laboratory to calculate the amount of total flavonoids present in the sample. To $0.5 \mathrm{~mL}$ of AIS, $0.5 \mathrm{ml}$ of $2 \%$ aluminium chloride solution was added. After $1 \mathrm{~h}$ at room temperature, the absorbance was read at $420 \mathrm{~nm}$ using a UV-spectrophotometer, and expressed as $\mathrm{mg}$ of RE/g of extract. Estimation of total flavonoid in the extracts was carried out in triplicates. Commercial rutin standard was used this assay.

\section{ABTS free radical scavenging activity}

For ABTS assay, the method of Re et al. [14] was adopted with some modifications. The stock solutions included $7 \mathrm{mM}$ ABTS solution and $2.4 \mathrm{mM}$ potassium persulfate solution was prepared first. The working solution was then prepared by mixing the two stock solutions in equal quantities and allowing them to react for $12 \mathrm{~h}$ at room temperature in the dark condition. The solution was then diluted by mixing $1 \mathrm{~mL}$ ABTS solution with $40 \mathrm{~mL}$ of methanol to obtain an absorbance of $0.706 \pm 0.002$ units at $734 \mathrm{~nm}$ using a spectrophotometer. AIS $(1 \mathrm{~mL})$ of various concentrations ranging from 20 to $100 \mu \mathrm{g}$ were allowed to react with $1 \mathrm{~mL}$ of the ABTS solution after $7 \mathrm{~min}$ the absorbance was read at $734 \mathrm{~nm}$ using the spectrophotometer. ABTS scavenging capacity of the extract was compared with that of BHT standard and percentage of inhibition calculated as:

\section{ABTS radical scavenging activity $(\%)$ $=[($ Abs control-Abs sample $)] /($ Abs control $)] \times 100$}

Where Abs control is the absorbance of ABTS radical + methanol; Abs sample is the absorbance of ABTS radical + sample extract/standard. The sample concentration providing $50 \%$ inhibition $\left(\mathrm{IC}_{50}\right)$ was 
calculated from the graph of inhibition percentage against sample concentration. All determinations were carried out in triplicates. ABTS radical-scavenging activity of BHT was also assayed for comparison.

\section{DPPH free radical scavenging activity}

Effect of extract on DPPH radical was estimated using the method of Liyana-Pathiranan and Shahidi [15]. A solution of $0.135 \mathrm{mM}$ DPPH in methanol was prepared and $1 \mathrm{~mL}$ of this solution was mixed with AIS $(1 \mathrm{~mL})$ of various concentrations ranging from 20 to $100 \mu \mathrm{g}$. The reaction mixture was vortexed thoroughly and left in the dark at room temperature for $30 \mathrm{~min}$. Absorbance of the mixture was read spectrophotometrically at $517 \mathrm{~nm}$. BHT was used as reference standard. The ability to scavenge DPPH radical was calculated by the following equation

$$
\begin{aligned}
& \text { DPPH radical scavenging activity }(\%) \\
& \quad=[(\text { Abs control-Abs sample })] /(\text { Abs control })] \times 100
\end{aligned}
$$

where Abs control is the absorbance of DPPH radical + methanol; Abs sample is the absorbance of DPPH radical + sample extract/standard. All determinations were carried out in triplicates.

\section{Determination of reducing power activity}

Reducing power of the AIS was determined according to the method of Oyaizu [16]. One $\mathrm{mL}$ of AIS of various concentrations $(20-100 \mu \mathrm{g})$ mixed with phosphate buffer ( $2.5 \mathrm{~mL}, 0.2 \mathrm{M}, \mathrm{pH} 6.6)$ and $2.5 \mathrm{~mL}$ of $1 \%$ potassium ferricyanide. The mixture was incubated at $50^{\circ} \mathrm{C}$ for 20 min. Then $2.5 \mathrm{~mL}$ of $10 \%$ trichloroacetic acid was added to the mixture, and centrifuged at $3000 \mathrm{rpm}$ for $10 \mathrm{~min}$. The supernatant $(2.5 \mathrm{~mL})$ was mixed with $2.5 \mathrm{~mL}$ distilled water and $0.5 \mathrm{~mL}$ of $0.1 \%$ ferric chloride. Absorbance was measured at $700 \mathrm{~nm}$ using a spectrophotometer. Increased absorbance of the reaction mixture indicated increased reducing power.

\section{Polyphenolic compounds identification using HPLC analysis}

Identification of polyphenolic compounds from AIS using RP-HPLC with $\mathrm{C}_{18}$ column $(4.6 \times 250 \mathrm{~mm}, 5 \mu \mathrm{m}$ particle size). HPLC system was coupled with a PDA detector (PDA-2998), Waters, USA. Mobile phase consist of HPLC water with $0.1 \%$ formic acid (Solvent A) and $100 \%$ methanol (HPLC grade) (Solvent B). Gradient elution program followed; Solvent A and B was 0-10\% (5 min), $10-15 \%$ (5 min), $15-20 \%$ (5 min), 20-30\% (5 min), 30-40\% (5 min); Flow rate was $1 \mathrm{~mL} / \mathrm{min}$ and maximum pump pressure 4000 psi was maintained. Polyphenolics were identified at wavelength of $280 \mathrm{~nm}$ [17]. Compounds were identified and confirmed by comparing its $t R$ and $\lambda$ max compared with commercial standard.

\section{In vivo studies \\ Acute toxicity test}

To evaluate the acute toxicity of AIS, a single oral dose of AIS of various concentrations $0.5,1,1.5,2,2.5$ and $3.0 \mathrm{~g} / \mathrm{kg}$ b.w. was given to Wistar rats then allowed free access to food and water. The animals were observed for signs of toxicity such as, urination, salivation, asthenia and defaecation for $72 \mathrm{~h}$ after the oral administration for the acute oral toxicity. AIS was safe up to the dose of 2 g/kg b.w. p.o. for Wistar rats and did not show any acute toxicity signs. We chose a wide concentration range for AIS in our preliminary study and their inhibitory effects against $\mathrm{CCl}_{4}$ induced hepatotoxicity were evaluated (data not shown). By avoiding non effective and toxic concentrations, the 250 and $500 \mathrm{mg} / \mathrm{kg}$ b.w. concentrations were selected. Experimental protocols were approved by the CPCSEA, Chennai, Tamil Nadu, India (BDU/IAEC/ 2012/29).

\section{Treatment}

Animals were randomly divided into five groups of 6 rats per group. Group I served as normal control and was given olive oil ( $1 \mathrm{~mL} / \mathrm{kg}$ of b.w.) daily for a period of 8 weeks. For inducing hepatotoxicity (in vivo), animals of Groups II-V were administered orally $1 \mathrm{~mL} / \mathrm{kg}$ of b.w. of $\mathrm{CCl}_{4}\left(1: 1, v / \mathrm{v}, \mathrm{CCl}_{4}\right.$ in olive oil) twice a week for 8 weeks. Group II served as $\mathrm{CCl}_{4}$-treated model group (disease control). Group III received silymarin (at $50 \mathrm{mg} / \mathrm{kg}$ of b.w.) daily for a period of 8 weeks, which served as positive control. Groups IV and V were administered orally with AIS at 250 and $500 \mathrm{mg} / \mathrm{kg}$ of b.w. daily for 8 weeks [18]. At the end of the experiment, all animals were sacrificed. Serum samples were collected into heparinized tubes $(50 \mathrm{U} / \mathrm{mL})$. Liver samples were dissected out and washed immediately with ice cold saline to remove as much blood as possible. One part of the liver samples was immediately stored at $-20{ }^{\circ} \mathrm{C}$ until analysis, another part was excised and fixed in $10 \%$ formalin solution for histopathological analysis.

\section{Determination of serum biochemical parameters}

Serum biochemical parameters such as SGOT, SGPT, ALP and bilirubin were estimated in the serum of experimental animals using commercial reagent kits and were performed according to the manufacturer's (Nice Chemicals [P] Ltd. Cochin, Kerala, India) instructions.

\section{Antioxidant enzymes activities}

Liver homogenates $(10 \% \mathrm{w} / \mathrm{v})$ prepared in phosphate-buffered saline (PBS containing $137 \mathrm{mM}$ sodium chloride, 2.68 $\mathrm{mM}$ potassium chloride, $10.14 \mathrm{mM}$ sodium phosphate 
dibasic and $1.76 \mathrm{mM}$ potassium phosphate monobasic in $1000 \mathrm{~mL}$ distilled water $\mathrm{pH}$ 7.2) were used for antioxidant studies. Catalase activity was determined by the method of Sinha [19] in which dichromatic acetic acid is reduced to chromic acetate when heated in the presence of hydrogen peroxide, with the formation of perchloric acid as an unstable intermediate. The green colour developed was read at $590 \mathrm{~nm}$ against blank on a spectrophotometer. CAT activity was expressed as units $/ \mathrm{mg}$ protein ( $\mathrm{mmoL}$ of hydrogen peroxide consumed $/ \mathrm{min} / \mathrm{mg}$ protein). SOD activity was determined by the method of Marklund and Marklund [20]. The degree of inhibition of pyrogallol auto-oxidation by the supernatant of the tissue homogenate or haemolysate was measured. The change in absorbance was read at $470 \mathrm{~nm}$ against blank every minute for $3 \mathrm{~min}$ using a spectrophotometer. Enzyme activity was expressed as $\mathrm{U} / \mathrm{mg}$ of protein. GSH content was estimated by the method of Moron et al. [21]. To the supernatant of the tissue homogenate, $0.5 \mathrm{~mL}$ of $10 \%$ trichloroacetic acid was added followed by centrifugation. To the resulting protein-free supernatant, $4 \mathrm{~mL}$ of 0.3 $\mathrm{M}$ sodium phosphate dibasic $(\mathrm{pH} 8.0)$ and $0.5 \mathrm{~mL}$ of $0.04 \%$ $(w / v)$ 5, 5-dithiobis-2-nitrobenzoic acid were added. Absorbance of the resulting yellow colour was read spectrophotometrically at $412 \mathrm{~nm}$. Results were expressed as $\mu \mathrm{g} / \mathrm{mg}$ protein.

\section{Determination of lipid peroxidation level}

The mean concentration of MDA, a measure of the intensity of lipid peroxidation, was assayed in the form of thiobarbituric acid reacting substances (TBARS) by the method of Ohkawa et al. [22]. Briefly, to $0.2 \mathrm{~mL}$ of $8.1 \%$ sodium dodecyl sulphate, $1.5 \mathrm{~mL}$ of $20 \%$ acetic acid $(\mathrm{pH}$ 3.5 ) and $1.5 \mathrm{~mL}$ of $0.81 \%$ thiobarbituric acid aqueous solution were added in succession. To this reaction, 0.2 $\mathrm{mL}$ of tissue homogenate was added separately. This mixture was then heated in a boiling water bath for 60 min. After cooling to room temperature, $5 \mathrm{~mL}$ of butanol:pyridine $(15: 1, v / \mathrm{v})$ solution was added. The mixture was then centrifuged at $2000 \mathrm{x}$ g for $15 \mathrm{~min}$. Upper organic layer was separated and the intensity of the resulting pink color was read at $532 \mathrm{~nm}$. Tetramethoxypropane was used as an external standard. The level of lipid peroxides was expressed as nanomoles of MDA formed/mg protein.

\section{Histological studies}

Liver samples were fixed in Bouin's fixative and processed to obtain $5 \mu \mathrm{m}$ thick paraffin sections and stained with hematoxylin and eosine (H\&E) for histological observations.

\section{Statistical analysis}

Statistical analysis was performed using the statistical package SPSS (Statistical Package for Social Science,
SPSS Inc., Chicago, IL, USA). Analysis of variance was performed by ANOVA procedures and significance of each group was verified with one-way analysis of variance followed by Duncan post hoc test $(P \leq 0.05)$. Values obtained are means of six replicate determinations \pm standard deviation.

\section{Results}

Preliminary phytochemical analysis

Preliminary phytochemical analysis [18] of AIS revealed the presence of phenolics, flavonoids, steroids, tannins, saponins and terpenoids. Total phenolics and flavonoid content of AIS were $20.78 \pm 0.86 \mathrm{mg}$ of GAE/g of the extract and $17.78 \pm 0.45 \mathrm{mg}$ of RE/g of extract respectively.

\section{Free radical scavenging activity}

Inhibition range of ABTS (Fig. 1a) and DPPH (Fig. 1b) free radicals by AIS are shown in Figures. The quenching effect of AIS against ABTS and DPPH radicals in a dose dependent manner is clearly depicted in the result obtained. $\mathrm{IC}_{50}$ values of AIS to quench ABTS and DPPH radicals are $32.08 \pm 0.12$ and $45.24 \pm 0.65 \mu \mathrm{g} / \mathrm{mL}$, respectively.

\section{Reducing power activity}

The reducing potential of the AIS was shown in Fig. 2 in comparison with a standard BHT at $700 \mathrm{~nm}$. In the reducing power assay, the principle is the ability of the antioxidants present in the sample to reduce $\mathrm{Fe}^{3+}$ to $\mathrm{Fe}^{2+}$ by donating an electron and results in the formation of perl's blue coloured solution. The intensity of the colour formed can be measured at $700 \mathrm{~nm}$. The reducing effect of the extract can be predicted by increase in absorbance in dose dependent manner. The reducing capacity of AIS increases proportionally with increase in the concentration of the extract used. The results shows that the reducing at $100 \mu \mathrm{g} / \mathrm{mL}$ concentration had an optical density of 0.4274 , which was comparatively similar to that of the standard BHT with an optical density of 0.4766 .

\section{HPLC identification of polyphenolic compounds}

A typical HPLC profile of the phenolic and flavonoids constituents of AIS was presented in Fig. 3. HPLC analysis of AIS showed that phenolic compounds such as protocatechuic acid, chlorogenic acid, caffeic acid, vanillin and $\mathrm{p}$-Coumaric acid and also flavonoids such as naringinin, qurecetin, rutin and flavon were detected (Fig. 3c). Flavonoids are the most abundant phytocompounds present in the AIS as compared with phenolic compounds. Chromatograms revealed some unidentified peaks that may correspond to unknown phenolic compounds. 

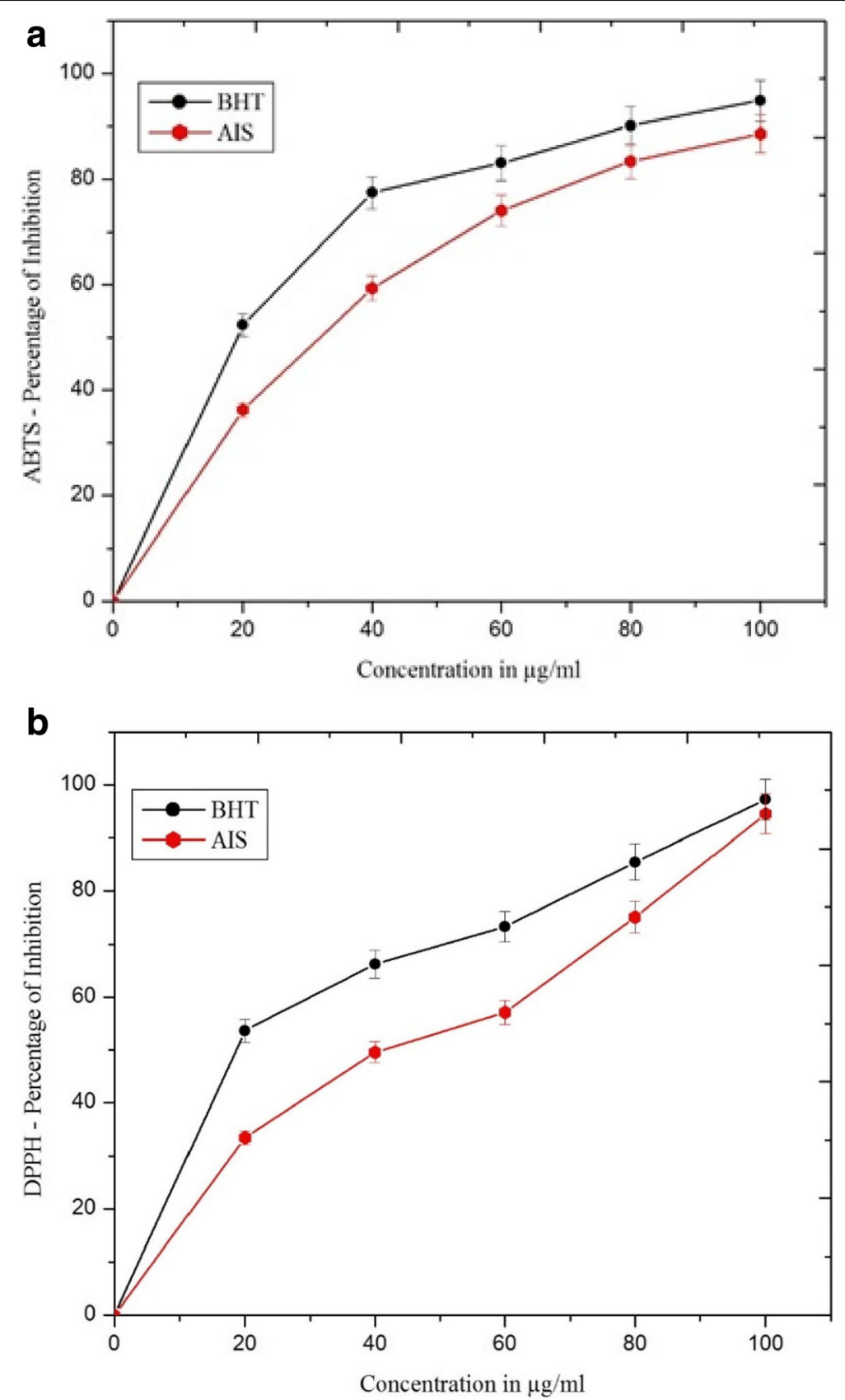

Fig. 1 a Antioxidant activity of AIS. a ABTS ${ }^{+}$radical scavenging activity of AIS compared with BHT. Each value is expressed as the mean \pm standard deviation $(n=3)$. b DPPH radical scavenging activity of AIS compared BHT. Each value is expressed as the mean \pm standard deviation $(n=3)$

\section{In vivo studies}

\section{Serum biochemical parameters}

Mean serum activities of SGOT, SGPT, ALP, and bilirubin were found to be higher in samples from Group II rats (Disease control) when compared to values in samples from Group I (Normal control) rats. However, the mean serum activities of above mentioned parameters were significantly $(P \leq 0.05)$ lower in groups treated with AIS (500 mg/kg b.w) and silymarin (Table 1).

\section{Antioxidant enzyme activities}

$\mathrm{CCl}_{4}$ treatment caused a significant decrease in the level of tissue antioxidant enzymes such as SOD, CAT, and the cellular antioxidant molecule GSH in liver [23]. AIS administration has up regulated the activities of these endogenous antioxidant enzymes (Table 1). The levels of liver SOD, CAT, and GSH in the $\mathrm{CCl}_{4}$-treated group were less compared with the normal control group. The result obtained indicates the tremendous increase $(P \leq 0.05)$ in 


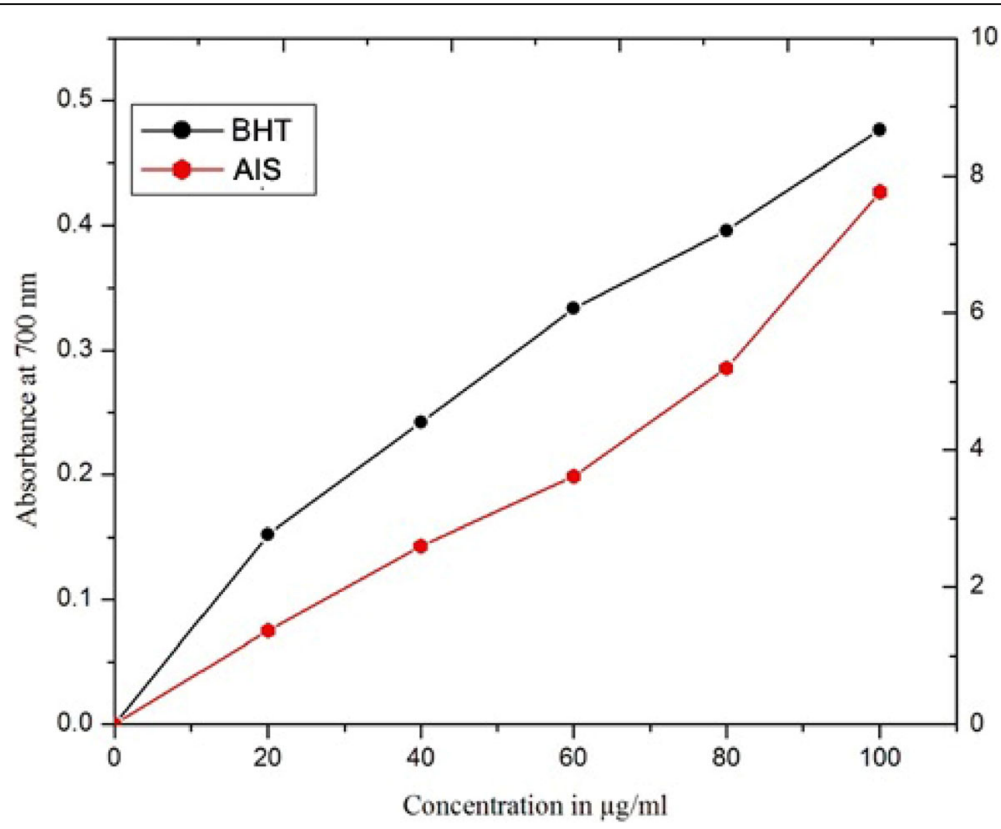

Fig. 2 Reducing power of AIS compared with BHT. Each value is expressed as the mean \pm standard deviation $(n=3)$

SOD, CAT and GSH activity in the AIS treated groups (at $500 \mathrm{mg} / \mathrm{kg}$ b.w.). The activity of AIS at the dose of $500 \mathrm{mg} / \mathrm{kg}$ was comparable to that of the positive control, silymarin. Reduced glutathione is presumed to be an important endogenous defense against peroxidative destruction of cellular membranes. In the present study, $\mathrm{CCL}_{4}$ administrated animals shows decline in the presence of reduced glutathione level. Treatment with AIS was very effective in restoring the glutathione content which had been substantially decreased in $\mathrm{CCl}_{4}$ group (Table 1 ). Significantly $(P \leq 0.05)$ higher MDA level was noted in tissue samples obtained from $\mathrm{CCL}_{4}$ administrated (Group II) rats than in those from normal (Group I) rats, whereas the mean levels of MDA in samples from AIS-treated groups (Group IV and Group V) were significantly $(P \leq 0.05)$ lower than the levels in samples from (Group II) rats given in Table 1.

\section{Histopathological examination}

The report of histopathological studies supports the results of the biochemical studies and it demonstrates that the hepatic damage caused by $\mathrm{CCl}_{4}$ during intoxication is reduced in the liver sample of animals treated with AIS. Histological examination of the liver sections of control animals revealed the presence of normal hepatocytes with well-preserved cytoplasm, a prominent nucleus and distinct sinusoidal spaces (Fig. 4a). $\mathrm{CCl}_{4}$ treated groups liver tissue cells show severe damage to liver tissue by cell necrosis (Fig. 4b). Interestingly, the administration of AIS against this liver damage shows protective capacity of AIS against liver necrosis. AIS at a dose of $500 \mathrm{mg} / \mathrm{kg}$ b.w. was more effective when compared to the other dose $(250 \mathrm{mg} / \mathrm{kg}$ bw) (Fig. 4c)and also showed regaining of normal histological appearance (Fig. $4 \mathrm{~d}$ ), which clearly indicates the protective and curative effect of AIS against $\mathrm{CCl}_{4}$-induced hepatic damage. The standard, silymarin-treated rats liver section showed almost normal liver with no sign of necrosis (Fig. 4e).

\section{Discussion}

Phenolic compounds acting as antioxidants present in the plant products are gaining attention among different people due to their health benefits. In this study, antioxidant assays like ABTS, DPPH and reducing power assays have been carried to explore the antioxidant activity of AIS. These assays are the mostly used common assays by researchers to evaluate the antioxidant capacity of samples from plants. In the present study, scavenging activity of AIS on DPPH and ABTS radicals were observed in a concentration-dependent pattern. The antioxidant ability of the secondary metabolites of plants is also related to its reducing capacity [24]. As already discussed above, the reducing capacity of a substance is based on the reduction of the complex compound ferric tripyridyl triazine $\left(\mathrm{Fe}^{3+}\right.$-TPTZ) to ferrous tripyridyl triazine $\left(\mathrm{Fe}^{2+}\right.$-TPTZ), which results in the formation of coloured solution. Reducing power efficacy of the AIS increases in a concentration dependant manner. Due to the chemical complexity of plant extract, the isolation and quantification of polyphenolic compounds are very difficult. HPLC is an important analytical method in 


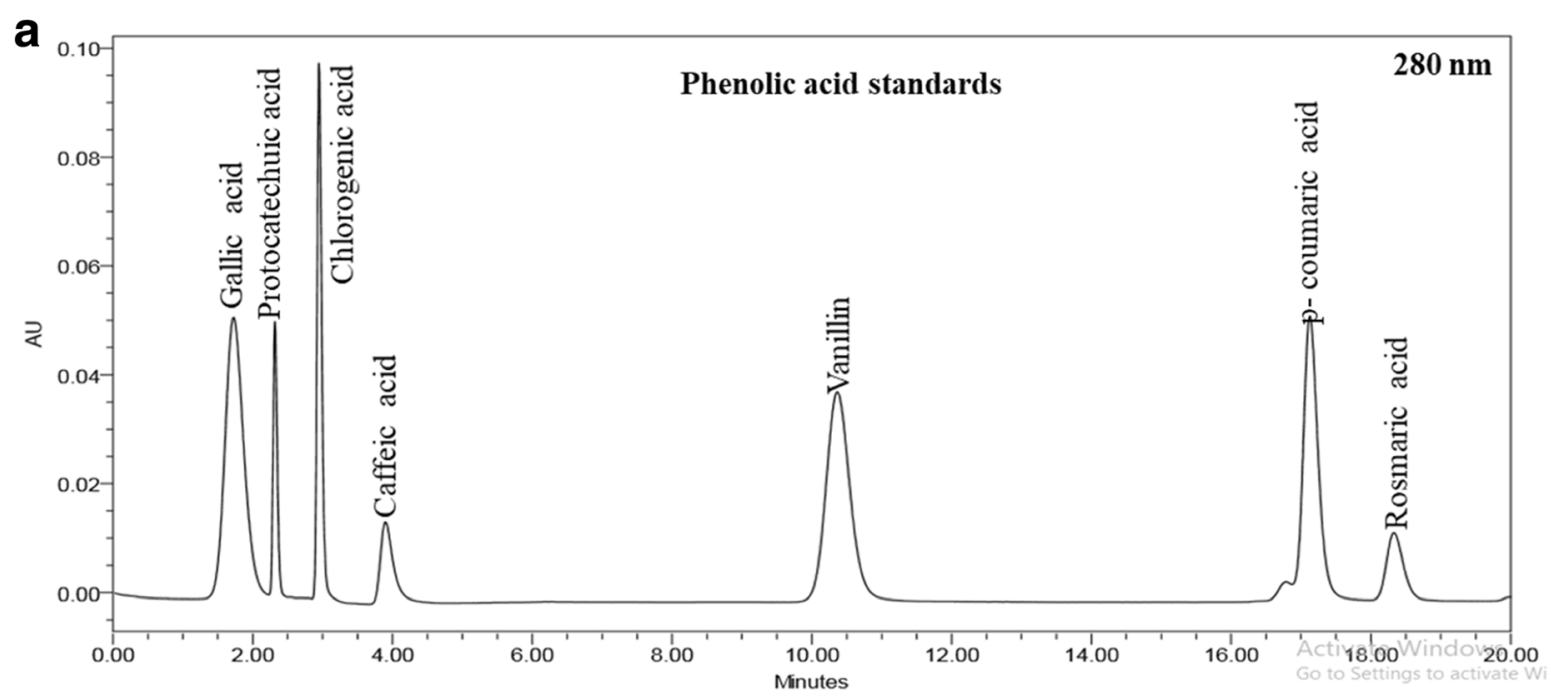

b
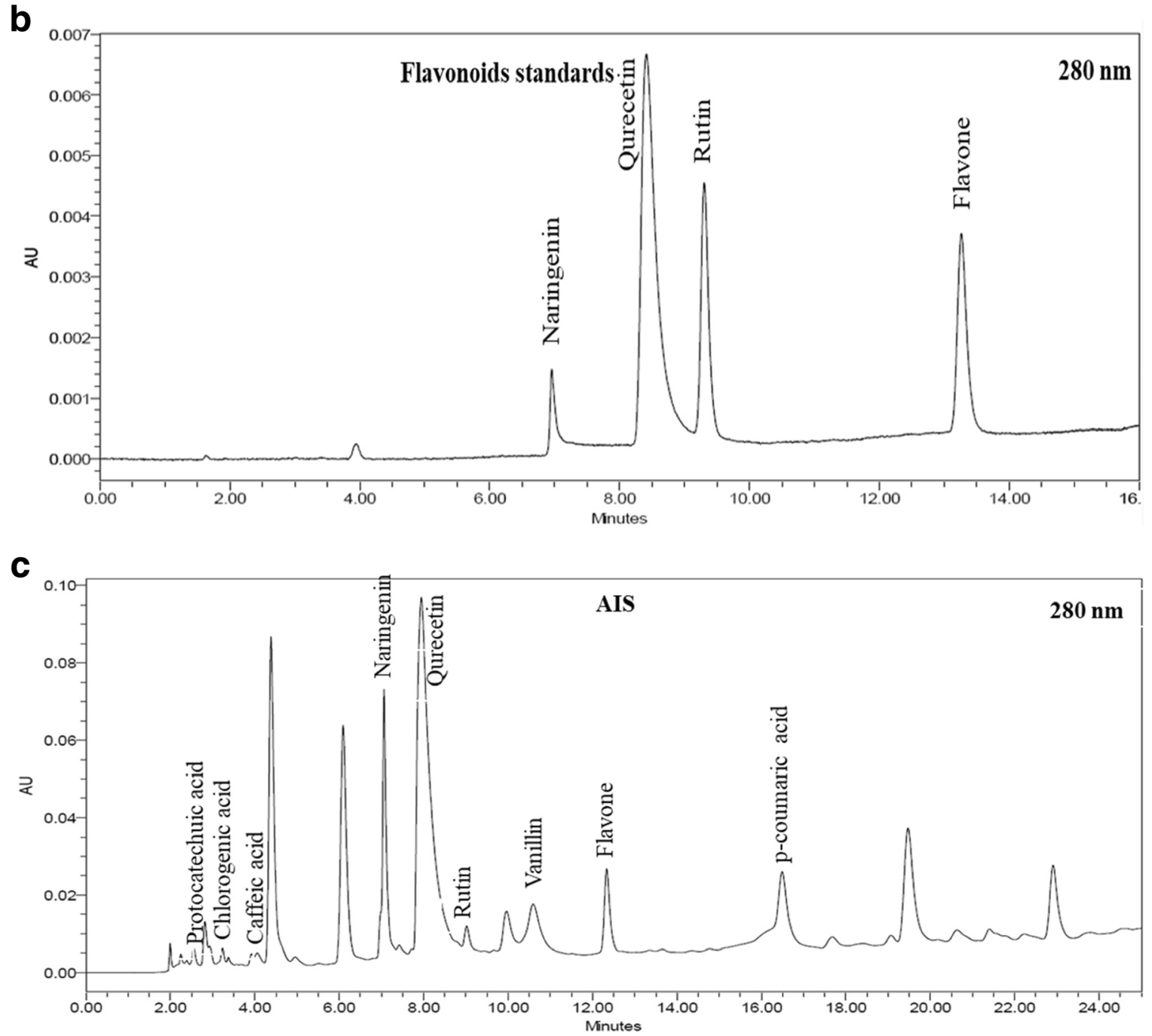

Fig. 3 HPLC profiling of polyphenolic compounds identified in AIS 


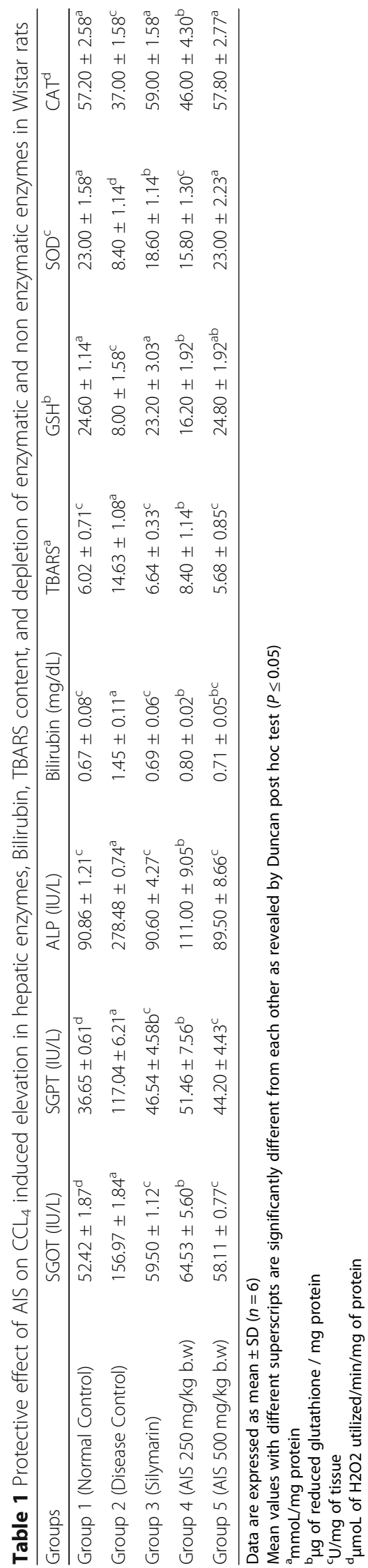



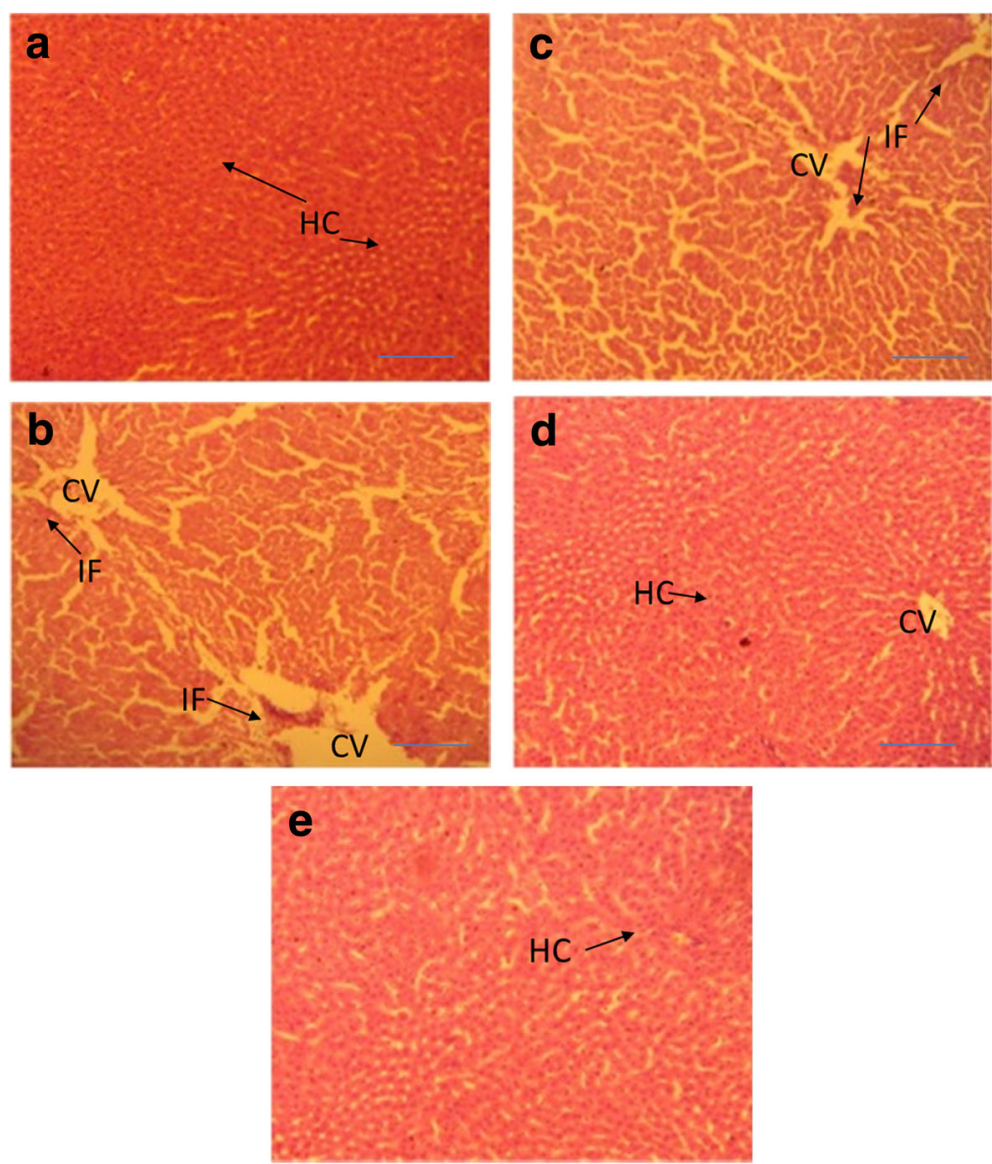

Fig. 4 Histopathological analysis of liver tissue of male Wistar rats administrated with $\mathrm{CCl}_{4}$ and treated with AlS. a Control group shown normal lobular architecture with clear central vein $(X-40)$. $\mathbf{b} \mathrm{CCl}_{4}$ administered group shown severe hepatocyte necrosis, fatty degeneration and vacuolation (X-40). c AlS treated group at $250 \mathrm{mg} / \mathrm{kg}$ shown mild improvement in chord arrangement but perinuclear vacuolation was visible (X40). d AIS treated group at $500 \mathrm{mg} / \mathrm{kg}$ shown normal cellular architecture with distinct hepatic cells sinusoidal spaces (X-40). e Silymarin (positive drug) treated group exhibited almost normal histology (X-40); Hepatocytes (HC), Central vein (CV) and Cellular inflammation (IN)

identification of bioactive compounds from plant sources. In this study we identified important bioactive compounds using HPLC. These phytochemicals have effective antioxidant potential to treat various human diseases [25]. Antioxidant properties of bioactive compounds (phenolics and flavonoids) are responsible for the hepatoprotection by plant extracts. These compounds effectively reduce the oxidative stress and other inflammatory responses [26, 27].

Protective effect of AIS was further evaluated in $\mathrm{CCl}_{4}$ - induced oxidative stress in the livers of Wistar rats by observing the histological and biochemical changes in rats. The liver injury caused by $\mathrm{CCl}_{4}$ is mainly by the release of free radicals, which are generated during the metabolism of $\mathrm{CCL}_{4}$ by the cytochrome P450 (CYP) system. The content of CYP in liver is more abundant than that in other organs such as lung, kidney, and intestine. By the activation of liver $\mathrm{CYP}$, by $\mathrm{CCl}_{4}$ intoxication produces hepatotoxic metabolite trichloromethyl free radicals $\left(\cdot \mathrm{CCl}_{3}\right.$ or $\mathrm{CCl}_{3} \mathrm{OO} \bullet$ ), which immediately propagate a chain of lipid peroxidation events and ultimately leads to the breakdown of membrane structure and result in the leakage of hepatic cell marker enzymes into the blood. In our study, significant increase $(P \leq 0.05)$ in the levels of hepatic enzymes such as SGOT, SGPT, ALP and bilirubin were observed in serum sample of experimental animals after administration of $\mathrm{CCl}_{4}$. The increased levels of liver enzymes in blood of rats administrated with $\mathrm{CCL}_{4}$ were reduced by the treatment with AIS. The degree of liver cell membrane damage is known clinically by the increased activity of SGOT, SGPT, and ALP enzyme in serum. The hepatic TBARS level is also commonly used as an indicator of liver tissue damage which involves a series of chain reactions [28]. In our results, rats treated with $\mathrm{CCl}_{4}$ showed an increase in TBARS which was restored towards normal by the treatment with AIS.

Antioxidant enzyme such as SOD converts superoxide anion into $\mathrm{H}_{2} \mathrm{O}_{2}$ and $\mathrm{O}_{2}$, whereas CAT reduces $\mathrm{H}_{2} \mathrm{O}_{2}$ to $\mathrm{H}_{2} \mathrm{O}$, resulting in the quenching of free radicals. SOD 
and CAT plays an important role in the elimination of ROS derived from the redox process in liver tissues and considered to be most important enzymes [29]. Intoxication with $\mathrm{CCl}_{4}$ to Wistar rats reduced the antioxidant capacity of rat liver by inhibiting the enzymatic activity of SOD and CAT. However, treatment with AIS improved the levels of these enzymes significantly in a dose dependent manner (250 and $500 \mathrm{mg} / \mathrm{kg} \mathrm{b.w)}$. The activity of AIS was directly proportional to the increased concentration, suggesting that it could offer protection against hepatic damage caused by toxic substances. $\mathrm{CCl}_{4}$ administration reduces the level of GSH in liver tissue of rats. Administration of AIS as a drug to treat hepatic damage significantly increased the GSH content in liver tissue $(P \leq 0.05)$. Similarly hydroalcoholic extract of $I$. staphylina leaves significantly decreased the serum urea, creatinine, uric acid and protein levels in treated groups, which strongly supports our data [30]. In support with the results of biochemical parameters, treatment with AIS reduced the histological alteration induced by $\mathrm{CCl}_{4}$.

\section{Conclusion}

Our study demonstrated that the AIS leaves showed favorable potency to protect the liver damage induced by $\mathrm{CCl}_{4}$, which suggested that I. staphylina can be used as a potential hepatoprotective drug. The hepatoprotecive activity of AIS against severe damage caused by $\mathrm{CCL}_{4}$ intoxication was clearly proved by the results obtained. This is mainly achieved by its ability to neutralize the free radicals. Simultaneously inflammatory responses were suppressed and improved activity of drug-metabolizing enzyme is noted well from the results obtained. HPLC results revealed that I. staphylina extract have potential bioactive secondary metabolites. Future studies are in progress to better understand the mechanism of action of bioactive compounds in AIS responsible for its hepatoprotective and antioxidant effects.

\footnotetext{
Abbreviations

\%: percentage; ${ }^{\circ} \mathrm{C}$ : degree Celsius; ABTS: 2, 2-azino-bis (3-ethylbenzthiazoline6-sulphonic acid); AlS: Ipomoea staphylina leaves aqueous extract; ALP: Alkaline phosphatase; b.w.: body weight; BHT: Butylated hydroxyltoluene; CAT: Catalase; $\mathrm{CCl}_{4}$ : Carbon tetrachloride; CPCSEA: Committee for the Purpose of Control and Supervision of Experiments on Animals; DPPH: 2, 2-diphenyl-1-picrylhydrazyl; GAE: Gallic acid equivalent; GSH: Glutathione; h: hours; Kg: kilogram; LPO: Lipid peroxidation; M: Molar; MDA: Malondialdehyde; mg: milligram; min: minutes; mL: milliliter; $\mathrm{mM}$ \& mmoL: millimolar; NAPDH: Nicotinamide adenine dinucleotide phosphate; nm: nanometer; PDA: Photo Diode Array; psi: Pounds per square inch; RE: Rutin equivalent; ROS: Reactive oxygen species; RP-HPLC: Revere Phase High Performance Liquid Chromatography; rpm: rotation per minute; SGOT: Serum glutamate oxaloacetate transaminase SGPT: Serum glutamate pyruvate transaminase; SOD: Superoxide dismutase; TBARS: Thiobarbituric acid reacting substances; tR: Retention time; U: units; $v /$
}

v: volume/volume; $\lambda$ max: Absorbance spectrum; $\mu \mathrm{g}$ : microgram; $\mu \mathrm{L}$ : microliter; $\mu \mathrm{moL}$ : micromolar

\section{Acknowledgements}

We thank Dr. J. Senthilkumar, Veterinary Surgeon and Dr. R. Banumathi for their assistance in interpretation of histological results. Finally we sincerely thank UGC and DST-FIST, India for providing instrument facility.

\section{Funding}

No funding.

Availability of data and materials

The datasets supporting the conclusions of this article are included within the article.

\section{Authors' contributions}

RJ \& Dr. DAA have conducted all the experiments. TS has edited the manuscript. All authors read and approved the final manuscript.

\section{Ethics approval and consent to participate}

Experimental procedures and protocols were approved by the committee for the purpose of Control and supervision of experiments on animals, Chennai, Tamil Nadu, India.

Consent for publication

Not applicable.

\section{Competing interests}

The authors declare that they have no competing interests.

\section{Publisher's Note}

Springer Nature remains neutral with regard to jurisdictional claims in published maps and institutional affiliations.

\section{Author details}

'Department of Environmental Biotechnology, Bharathidasan University, Tiruchirappalli, Tamil Nadu 620024, India. ${ }^{2}$ Department of Food Quality \& Safety, Gilat Research Center, Agricultural Research Organization, Beer Sheba 85280 , Israel.

Received: 2 November 2018 Accepted: 7 April 2019 Published online: 26 April 2019

\section{References}

1. Shaker ME, Zalata KR, Mehal WZ, Shiha GE, Ibrahim TM. Comparison of imatinib, nilotinib and silymarin in the treatment of carbon tetrachlorideinduced hepatic oxidative stress, injury and fibrosis. Toxicol Appl Pharmacol. 2011;252:165-75.

2. Halliwell B, Gutteridge JMC. Free radicals in biology and medicine. Oxford: Clarendon Press; 1989. p. 96-8.

3. Halliwell B, Gutteridge JM. 1990. Role of free radicals and catalytic metal ions in human diseases: an overview. Methods Enzymol 1990;186:1-8.

4. Gaur G, Alam MS, Jabbar Z, Javed K, Athar M. Evaluation of antioxidant activity of Cassia siamea flowers. J Ethnopharmacol. 2006;108:340-8.

5. Upur H, Amat N, Blazekovic B, Talip A. Protective effect of Cichorium glandulosum root extract on carbon tetrachloride-induced and galactosamine-induced hepatotoxicity in mice. Food ChemToxicol. 2009;47: 2022-30.

6. Saleem TSM, Chetty CM, Ramkanth S, Rajan VST, Kumar KM Gauthaman K. Hepatoprotective herbs - a review. Int J Biol Pharm Allied Sci. 2010;1:1-5.

7. Dahanukar SA, Kulkarni RA, Rege NN. Pharmacology of medicinal plants and natural products. Ind J Pharmacol. 2000;32:S81-S118.

8. Mullaicharam AR, Maheswari RU, Geetha K, Panicker PS, Chandralekha V. Hemorrhoids: a review. Res JPharm Technol. 2010;3:296-9.

9. Devi RS, Chitra M, Jayamathi P. Hepatoprotectivity and an antioxidant study of Ipomoea hederacea on experimentally induced hepatotoxic rats. Recent Res Sci Technol. 2010;2:17-9.

10. Mungole AJ, Awati R, Chaturvedi A, Zanwar P. Preliminary phytochemical screening of Ipomoea obscura $(L)$ - a hepatoprotective medicinal plant. Int J Pharm Tech Res. 2010;2:2307-12. 
11. Rameshkumar A, Sivasudha T, Jeyadevi R, Sangeetha B, Ananth DA, GSB A, Nagarajan N, Renganathan R, Kathiravan A. In vitro antioxidant and antimicrobial activities of Merremia emarginata using thio glycolic acidcapped cadmium telluride quantum dots. Colloids Surf B Biointerfaces. 2013;101:74-82.

12. Wolfe K, Wu X, Liu RH. Antioxidant activity of apple peels. J Agri Food Chem. 2003;51:609-14.

13. Ordonez AAL, Gomez JD, Vattuone MA, Isla MI. Antioxidant activities of Saisium edule (Jacq.) swart extracts. Food Chem. 2006;97:452-8.

14. Re R, Pellegrini N, Proteggente A, Pannala A, Yang M, Rice-Evans C. Antioxidant activity applying an improved ABTS radical cation decolorization assay. Free Radic Biol Med. 1999;26:1231-7.

15. Liyana-Pathiranan CM, Shahidi F. Antioxidant activity of commercial soft and hard wheat (Triticum aestivum L.) as affected by gastric pH conditions. J Agri Food Chem. 2005:53:2433-40.

16. Oyaizu M. Studies on products of the browning reaction antioxidative activities of browning reaction products prepared from glucosamine. JapJNutr Diabet. 1986;44:307-15.

17. Rameshkumar A, Sivasudha T, Jeyadevi R, Ananth DA, Pratheepa G. Effect of environmental factors [air and UV-C irradiation] on some fresh fruit juices. Europian Food Research and Technology. 2012;234:1063-70.

18. Jeyadevi R, Sivasudha T, Rameshkumar A, Harnly JM, Lin LZ. Phenolic profiling by UPLC-MS/MS and hepatoprotective activity of Cardiospermum halicacabum against $\mathrm{CCl}_{4}$ induced liver injury in Wistar rats. J Funct Food. 2013;5:289-98.

19. Sinha AK. Colorimetric assay of catalase. Anal Biochem. 1972:47:389-94.

20. Marklund S, Marklund G. Involvement of the superoxide anion radical in the auto-oxidation of pyrogallol and a convenient assay for superoxide dismutase. Biochim Biophys Acta. 1974;47:469-74.

21. Moron MS, Depierre JN, Mannervik V. Levels of glutathione reductase and glutathione S-transferase activities in rat lung and liver. Biochim Biophys Acta. 1979;582:67-8.

22. Ohkawa H, Ohishi N, Yagi K. Assay of lipid peroxides in animal tissue by thiobarbituric acid reaction. Anal Biochem. 1979;95:351-8.

23. Sheweita SA, El-Gabar MA, Bastawy M. Carbon tetrachloride changes the activity of cytochrome P450 system in the liver of male rats: role of antioxidants. Toxicol. 2001;169:83-92.

24. Orhan I, Kartal M, Abu-Asaker M, Senol FS, Yilmaz G, Sener B. Free radical scavenging properties and phenolic characterization of some edible plants. Food Chem. 2009:114:276-81.

25. Ananth DA, Tietel Z, Aseervatham GSB, Deviram G, Sivasudha T. Phytochemical and pharmacological status of indigenous medicinal plant Pedalium murex L. Biomed Pharmacother. 2018;103:1456-63.

26. Arif M, Fareed S, Rahman MA. Stress relaxant and antioxidant activities of acid glycoside from Spondias mangifera fruit against physically and chemically challenged albino mice. J Pharm Bioall Sci. 2016;8:58-63.

27. Iqbal SS, Mujahid M, Kashif SM, Khalid M, Badruddeen AM, Bagga P, Akhtar J, Rahman MA. Protection of hepatotoxicity using Spondias pinnata by prevention of ethanol-induced oxidative stress, DNA-damage and altered biochemical markers in Wistar rats. Integr Med Res. 2016:5:267-75.

28. Poli G. 1993. Liver-damage due to free-radicals. Br Med Bull 1993;49:604-620.

29. Chelikani P, Fita I, Loewen PC. Diversity of structures and properties among catalases. Cell Mol Life Sci. 2004;61:192-208.

30. Bag AK, Mumtaz SMF. Hepatoprotective and nephroprotective activity of hydroalcoholic extract of Ipomoea staphylina leaves. Bangladesh J Pharmacol. 2013;8:263-8.

\section{Submit your manuscript to a SpringerOpen ${ }^{\circ}$ journal and benefit from:}

- Convenient online submission

- Rigorous peer review

- Open access: articles freely available online

- High visibility within the field

- Retaining the copyright to your article

Submit your next manuscript at $>$ springeropen.com 